\title{
The use of pharmacogenetics in clinical practice for the treatment of individuals with HIV infection in Thailand
}

This article was published in the following Dove Press journal:

Pharmacogenomics and Personalized Medicine

5 November 2015

Number of times this article has been viewed

\author{
Asalaysa Bushyakanist ${ }^{\prime}$ \\ Apichaya Puangpetch ${ }^{2,3}$ \\ Chonlaphat Sukasem ${ }^{2,3}$ \\ Sasisopin Kiertiburanakul' \\ 'Department of Medicine, ${ }^{2}$ Division of \\ Pharmacogenomics and Personalized \\ Medicine, Department of Pathology, \\ Faculty of Medicine, Ramathibodi \\ Hospital, Mahidol University, \\ ${ }^{3}$ Laboratory for Pharmacogenomics, \\ Somdech Phra Debaratana Medical \\ Center (SDMC), Ramathibodi \\ Hospital, Bangkok, Thailand
}

Objectives: The objectives of this study were to describe the use of pharmacogenetics in clinical practice for the treatment of individuals with human immunodeficiency virus (HIV) infection and to determine the treatment outcomes of HIV-infected patients in whom pharmacogenetic testing was performed.

Methods: This study involves a retrospective collection of medical records of HIV-infected patients who attended Ramathibodi Hospital during January 2011 to November 2014 and in whom pharmacogenetic testing was performed. We reviewed patients' characteristics, reasons for pharmacogenomic testing, results of human leukocyte antigen-B* (HLA-B*) 5701, HLA$B^{*} 3505, H L A-B^{*} 4001, C Y P 2 B 6$, and antiretroviral drug (ARV) levels, treatment planning after the physicians were informed the results, and outcome after changing the treatment.

Results: A total of 103 HIV-infected patients with a median age of 46 (range, 20-85) years were enrolled, and $68.9 \%$ of them were male. The reasons for pharmacogenomic testing were having adverse drug reactions besides rash (37.9\%), screening before prescribing ARV (36.9\%), choice of next ARV (19.4\%), and confirmation of the cause of skin rash (5.8\%). After the physicians knew the results, they adjusted the treatment plan including changing the regimens, changing the ARV dose for avoiding toxicity, and stopping ARV. Among 45 patients, side effects, such as dizziness from efavirenz or rash from abacavir, were improved in 96.4\%. Among 27 patients, abnormal laboratory results, such as renal insufficiency from tenofovir or anemia from zidovudine, were improved and some returned to normal in 59.3\%. HIV RNA was undetectable after treatment adjustment in $94.9 \%$.

Conclusion: The benefits of pharmacogenetic testing are either guiding the initial drug regimen or individualizing regimen, increasing efficacy, and simultaneously avoiding adverse drug reactions. Use of pharmacogenetic testing in HIV-infected Thai adults should be considered.

Keywords: adverse drug reaction, antiretroviral drugs, clinical practice, HIV, pharmacogenetics, Thailand

\section{Introduction}

According to the World Health Organization report in 2013, 440,000 people (aged 15-49 years) are living with human immunodeficiency virus (HIV) and acquired immune deficiency syndrome (AIDS) in Thailand. ${ }^{1}$ Thailand has the highest adult HIV prevalence in the Southeast Asian region (1.1\%), which leads HIV infection to become one of the major public health problems. ${ }^{1}$ However, successful HIV transmission prevention and treatment efforts throughout the past 2 decades have reduced the number of annual new HIV infections from 143,000 in 1991 to 9,700 in 2011. ${ }^{2}$ According to the 2012 Global AIDS Response country progress report for Thailand, 225,272 (64.6\%) eligible adults and children living with HIV and AIDS are on antiretroviral therapy. ${ }^{3}$ Nevertheless,
Correspondence: Sasisopin

Kiertiburanakul

Department of Medicine, Faculty of Medicine, Ramathibodi Hospital, Mahidol University, 270 Rama VI Road,

Bangkok 10400, Thailand

Tel +6622010033

Fax +6622012232

Email sasisopin.kie@mahidol.ac.th 
antiretroviral drug (ARV) toxicity is significant and needs to be monitored. Impaired adherence, which is usually a consequence of persistent adverse drug reactions (ADRs) related to ARV, leads to suboptimal therapy such as therapy discontinuation and ultimately to treatment failure. Treatment failure is often causing significant morbidity and occasionally leading to mortality. ${ }^{4,5}$ The present knowledge reveals some adverse effects of ARV such as efavirenz (EFV) and abacavir being involved in individual genetic predisposition. There is individual variability in the disposition of ARV, and some of this variability may be caused by variant drug metabolism or transporter genes. Pharmacogenetic research is the study of variations in genes that predict the patient's drug reactions. The benefits of pharmacogenetic testing are guiding the initial drug regimen, increasing efficacy, and simultaneously avoiding ADRs. ${ }^{6}$

Cytochrome $\mathrm{P}(C Y P)$ 2B6 genotyping appears to be a promising approach toward the prediction of EFV toxicity and allows the recognition of patients being slow EFV metabolizers. ${ }^{7}$ Patients who have slow-metabolizing alleles are at risk of greater plasma exposure, central nervous system (CNS) side effects, and possibly EFV resistance after drug withdrawal. ${ }^{7}$ The CNS side effects range from headaches and dizziness to insomnia, hallucinations, acute mania, and psychosis. ${ }^{8}$ In a previous study that demonstrated outcome of 139 Thai patients coinfected with HIV and tuberculosis, CYP2B6 haplotype $* 1 / * 1$ was associated with low EFV concentration. ${ }^{9}$ In addition, $C Y P 2 B 6$ haplotypes $* 6 / * 6, * 1 / * 6$, and $* 5 / * 6$ were associated with high EFV concentration. ${ }^{9}$ Other three previous studies in HIV-infected Thai patients showed that the heterozygous/homozygous mutation associated with low EFV concentrations was $18492 \mathrm{~T}>\mathrm{C}$, and those associated with high EFV concentrations were $516 \mathrm{G}>\mathrm{T}, 785 \mathrm{~A}>\mathrm{G}$, and $21563 \mathrm{C}>\mathrm{T}^{8-10}$

In $5 \%-8 \%$ of patients initiating abacavir, a drug hypersensitivity reaction can develop within 6 weeks of treatment initiation. ${ }^{11,12}$ The routine screening of patients' genetic makeup before they are prescribed abacavir has markedly reduced the incidence of hypersensitivity reactions. ${ }^{13}$ Indeed, in the larger study, the association between human leukocyte antigen-B* $\left(H L A-B^{*}\right) 5701$ and abacavir hypersensitivity was confirmed in white people but not in Asian subjects. ${ }^{11}$ According to Thai guidelines by Thai AIDS Society, $H L A-B * 5701$ screening prior to starting therapy with abacavir was recommended. ${ }^{14}$ However, this laboratory testing is not widely available in Thailand due to high cost and limited infrastructure.

Other haplotypes associated with pharmacogenetics and adverse effects among HIV-infected Thai patients are
$H L A-B * 4001$ and $H L A-B * 3505$. $H L A-B * 4001$ is a genetic marker significantly associated with stavudine-associated lipodystrophy. ${ }^{15} H L A-B * 4001$ has a high specificity $(95.8 \%)$ and a positive predictive value $(88.9 \%)$. This genetic factor is indeed stronger than the factor of stavudine treatment duration (odds ratio: 9.26 vs $1.02,95 \%$ confidence interval: $1.98-88.11, P=0.001) .{ }^{15}$ Nevirapine (NVP) is still one of the common drugs used in resource-limited setting; however, the incidence of NVP-induced skin rash is as high as 21\%-38\% in Thailand. ${ }^{16} H L A-B * 3505$ is a strong genetic biomarker for identifying patients with high risk of NVP-induced skin rash in Thai populations (positive predictive value $92.6 \%$ and specificity $98.9 \%$ ). $H L A-B * 3505$ genetic test before the administration of NVP is expected to prevent a subset of patients from developing NVP-induced skin rash. ${ }^{17}$

In 2010, pharmacogenetic laboratory has been established at Faculty of Medicine Ramathibodi Hospital. We have 1,500 HIV-infected patients who are under follow-up at the hospital. Of these, 1,200 patients were receiving antiretroviral therapy. However, there are no data after the availability of these tests regarding their use in clinical practice for the treatment of HIV infection in Thailand. Thus, the aims of this study were to describe the use of pharmacogenetics in clinical practice for the treatment of individuals with HIV infection and to determine the treatment outcomes of HIV-infected patients in whom pharmacogenetic testing was performed.

\section{Methods}

This is a descriptive study of HIV-infected patients attending Ramathibodi Hospital, Bangkok, Thailand. All HIV-infected patients aged $>15$ years, attended infectious diseases clinic during January 2011 to November 2014, and in whom pharmacogenetic testing was performed were included in the study. We collected patients' demographic information, reasons for pharmacogenetic testing, symptoms of ADR (such as dizziness, insomnia or depression, skin rash, and fatigue), and the results of $H L A-B * 5701, H L A-B * 3505, H L A-B * 4001$, $C Y P 2 B 6$, and ARV levels. Other laboratory investigation reports were also collected for the following: CD4 cell count, HIV RNA, complete blood count, liver function test (alanine aminotransferase, aspartate aminotransferase, total bilirubin, direct bilirubin), and serum creatinine. Treatment planning after the physicians were informed the results, and outcome after changing the treatment were retrieved and reviewed. The study was approved by the ethical clearance committee on human rights related to research involving human subjects of the Faculty of Medicine Ramathibodi Hospital, Mahidol University (protocol number ID 08-56-03). 


\section{Genomic DNA extraction}

Blood samples were collected in ethylenediaminetetraacetic acid (EDTA) tubes. DNA was isolated using the MagNA Pure automated extraction system (Roche Diagnostics, Indianapolis, IN, USA), which uses magnetic bead technology with a lysis buffer and proteinase K. Nucleic acids bind to the surface of the magnetic glass particles. Cellular debris was removed by several washing steps, and the purified nucleic acids were eluted. From the $1 \mathrm{~mL}$ input volume of EDTA whole blood, $200 \mu \mathrm{L}$ output volume of extracted genomic DNA product was obtained. The quality of genomic DNA was assessed by using NanoDrop ${ }^{\circledR}$ ND-1000. Genomic DNA was detected by measuring absorbance at $260 \mathrm{~nm}$. Purity of the sample was evaluated by calculation of the optical density (OD) ratio, 260/280 nm. The recommended purified genomic DNA template for this study was $20 \mathrm{ng}$, and the OD ratio was $>1.7$. All DNA was aliquoted and stored at $-20^{\circ} \mathrm{C}$ before analysis.

\section{HLA-B typing}

$H L A-B$ genotyping was carried out using the Luminex ${ }^{\mathrm{TM}}$ Multiplex Technology (Luminex ${ }^{\circledR}$ IS 100, Luminex Corporation, Austin, TX, USA) based on polymerase chain reaction (PCR) sequence-specific oligonucleotides probe principles. Briefly, the PCR products were hybridized against a panel of oligonucleotide probes coated onto polystyrene microspheres. Probe sequences were complementary to stretches of polymorphic sequence within the target $H L A-B$ alleles. The amplicon-probe complex was visualized using a colorimetric reaction and fluorescence detection technology. Data analyses for the $H L A-B$ assays were performed with HLA Fusion ${ }^{\mathrm{TM}}$ 2.0 software.

\section{CYP2B6 genotyping}

Predesigned TaqMan assays (Thermo Fisher Scientific, Waltham, MA, USA) were used to genotype the CYP2B6 c.516G $>$ T (assay ID C_7817765_60), c.64C $>$ T (assay ID C_2818162_20), c.499C $>$ G (assay ID C_2752377_10), c.1375A $>$ G (assay ID C_2741754_10), c.1459C $>$ T (assay ID C_30634242_40), g.3003T >C (assay ID C_2818167_10), and g.21563C $>$ T (assay ID C_22275631_10). The genotyping of CYP $2 B 6$ c.785A $>\mathrm{G}$ was performed by custom TaqMan assays (Applied Biosystems). The sequences of primers and probes were the following: $C Y P 2 B 6$ c.785A $>$ G, TGGAGAAGCACCGTGAAACC (forward), TGGAGCAGGTAGGTGTCGAT (reverse), VIC-CCCCCAAGGACCTC-MGB (wild-type), and FAM-CCCCAGGGACCTC-MGB (mutant). For single-nucleotide polymorphism (SNP) analysis, this SNP was genotyped using allele-specific fluorogenic 5' nuclease chain reaction assay with predesigned primers and TaqMan MGB probes (TaqMan SNP Genotyping Assay; Thermo Fisher Scientific). Sequence-specific forward and reverse primers to amplify the polymorphic sequence of interest used two TaqMan MGB probes; one probe was labeled with VIC dye and detected the allele 1 sequence, and the second probe was labeled with FAM dye and detected the allele 2 sequence.

\section{Measurement of EFV plasma concentrations}

Plasma EFV level at 12 hours after dosing was measured using a validated high-performance liquid chromatography (HPLC) assay. Briefly, patient plasma samples $(300 \mu \mathrm{L})$ and all calibration and control samples were heat-inactivated in a water bath at $56^{\circ} \mathrm{C}$ for 30 minutes prior to assay. Sample pretreatment involved protein precipitation with acetonitrile $(360 \mu \mathrm{L})$, and following centrifugation, the sample supernatant was injected into the HPLC machine. Analysis was performed using an Agilent 1100 HPLC machine with an Omnispher C18 $(150 \mathrm{~mm} \times 4.6 \mathrm{~mm} \mathrm{ID} /$ particle size $5 \mu \mathrm{m})$ analytical column (Varian, Palo Alto, CA, USA), a ChromGuard RP guard column, and a mobile phase consisting of $10 \mathrm{mM} \mathrm{KH}_{2} \mathrm{PO}_{4}(\mathrm{pH}$ 3.1)-acetonitrile (50:50, v/v). The retention time for EFV was 5.1 minutes. The peak of this compound was well resolved and free of interference from endogenous compounds in the plasma. The lower limit of quantification of EFV is $0.2 \mathrm{mg} / \mathrm{L}$. The detection limit was defined as a signal-to-noise ratio of 3:1. The calibration standards for plasma samples were linear in the range of $0.2-20 \mathrm{mg} / \mathrm{L}$. Low-, medium-, and high-level quality control (QC) samples were prepared at $0.4 \mathrm{mg} / \mathrm{L}$, $1.5 \mathrm{mg} / \mathrm{L}$, and $10 \mathrm{mg} / \mathrm{L}$, respectively. The intra- and inter-day precision was within $0.0758 \%$ and $0.0091 \%$, respectively. The assay accuracy was $93 \%-104 \%$.

\section{Measurement of NVP plasma concentrations}

Calibration samples were prepared by spiking $90 \mu \mathrm{L}$ of blank plasma with $10 \mu \mathrm{L}$ of the different working standards to produce the matrix-matched calibration standards at concentrations of $100 \mathrm{ng} / \mathrm{mL}, 200 \mathrm{ng} / \mathrm{mL}, 500 \mathrm{ng} / \mathrm{mL}, 1,000 \mathrm{ng} / \mathrm{mL}$, $2,000 \mathrm{ng} / \mathrm{mL}, 3,000 \mathrm{ng} / \mathrm{mL}, 5,000 \mathrm{ng} / \mathrm{mL}$, and $10,000 \mathrm{ng} / \mathrm{mL}$ of NVP. Each sample also contained 3,000 $\mathrm{ng} / \mathrm{mL}$ of the internal standard (IS). In each calibration run, a plasma blank sample was also analyzed.

QC samples were prepared at three different concentration levels: low level $(75 \mathrm{ng} / \mathrm{mL})$, middle level $(250 \mathrm{ng} / \mathrm{mL})$, and high level $(4,000 \mathrm{ng} / \mathrm{mL})$. QC samples were prepared by spiking 
$90 \mu \mathrm{L}$ of blank plasma with $10 \mu \mathrm{L}$ of a standard solution. Each QC sample also contained 3,000 ng/mL of the IS.

EDTA blood samples were immediately centrifuged at 3,000 rpm for 15 minutes at $4{ }^{\circ} \mathrm{C}$ to separate the plasma, and an aliquot of $100 \mu \mathrm{L}$ of plasma sample was transferred to $1.5 \mathrm{~mL}$ tube. Each clinical plasma sample also contained $3,000 \mathrm{ng} / \mathrm{mL}$ of the IS.

Calibration, QC, and clinical plasma samples were extracted by protein precipitation. To all of the solutions was added $200 \mu \mathrm{L}$ of acetonitrile, and then, the mixtures were vortexed for 1 minute and centrifuged for 5 minutes at $15,000 \mathrm{rpm}$. The organic layer was removed and evaporated to dryness using evaporator at $45^{\circ} \mathrm{C}$. The residue was redissolved in $100 \mu \mathrm{L}$ mobile phase. The mixture was vortexed for 1 minute and centrifuged for 5 minutes at 15,000 rpm. Supernatant was transferred to a vial before injecting into the liquid chromatography-tandem mass spectrometry system.

\section{Definition}

- Therapeutic range of EFV is $1-4 \mu \mathrm{g} / \mathrm{mL} .^{18}$

- Therapeutic range of NVP is $3.7-5.7 \mu \mathrm{g} / \mathrm{mL}$.

- Acute kidney injury is defined as any of the following (not graded): increase in serum creatinine by $\geq 0.3 \mathrm{mg} / \mathrm{dL}$ ( $\geq 26.5 \mu \mathrm{mol} / \mathrm{L}$ ) within 48 hours; or increase in serum creatinine by $\geq 1.5$ times of baseline, which is known or presumed to have occurred within the prior 7 days; or urine volume $<0.5 \mathrm{~mL} / \mathrm{kg} / \mathrm{h}$ for 6 hours. ${ }^{19}$

- Anemia is defined as decrease in red blood cell mass: hematocrit $<41 \%$ or hemoglobin $<13.5 \mathrm{~g} / \mathrm{dL}$ in men and hematocrit $<36 \%$ or hemoglobin $<12 \mathrm{~g} / \mathrm{dL}$ in women. ${ }^{20}$

- Lipodystrophy is defined as abnormal or degenerative conditions of the body's adipose tissue which can be evaluated when three body areas are affected: sunken cheeks, thinning extremities, and thinning hips or buttocks. ${ }^{15}$

\section{Statistical analysis}

All relevant data were entered in Microsoft excel database. Missing data were treated as missing in the analysis. The data were analyzed using the statistical program Stata statistical software version 12.0 (StataCorp LP, College Station, TX, USA). Mean ( \pm standard deviation), median (interquartile range), and frequencies (\%) were used to describe patients' characteristics.

\section{Results}

During the study period, a total of $103 \mathrm{HIV}$-infected patients with a median age of 46 (range, 20-85) years were enrolled, and $68.9 \%$ of them were male. Median CD4 cell count at pharmacogenetic testing was 329 (range, 11-1,121) cells $/ \mathrm{mm}^{3}$. Most of them (97\%) were on ARV, and more than half had undetectable HIV RNA at the end of the study. The most common ARV regimen was tenofovir, lamivudine, and EFV (25\%). Patient characteristics are summarized in Table 1.

The reasons for pharmacogenetic testing were having ADRs besides rash (37.9\%), screening before prescribing ARV (36.9\%), choice of the next ARV (19.4\%), and confirmation of the cause of skin rash (5.8\%). Among 79 patients in whom $H L A$ testing was performed, the prevalence of $H L A$ $B * 5701, H L A-B * 3505$, and $H L A-B * 4001$ was $5.1 \%, 2.5 \%$, and $6.3 \%$, respectively (Table 2 ). Two out of four patients who had positive $H L A-B * 5701$ developed hypersensitivity after receiving abacavir (two of them received another ARV). One

Table I Demographic and baseline characteristics of 103 HIVinfected patients who performed pharmacogenetic testing

\begin{tabular}{|c|c|}
\hline \multicolumn{2}{|l|}{ Variables } \\
\hline Median (range) age at time of diagnosis (years) & $46(20-85)$ \\
\hline \multicolumn{2}{|l|}{ Sex, n (\%) } \\
\hline Male & 71 (68.9) \\
\hline Female & $32(31.1)$ \\
\hline \multicolumn{2}{|l|}{ At pharmacogenetic testing } \\
\hline Median (range) HIV RNA (copies/mL) & $8,261(19-2,670,000)$ \\
\hline Undetectable ( $<40$ copies $/ \mathrm{mL}$ ), n (\%) & $54(52.4)$ \\
\hline Detectable, n (\%) & $29(28.2)$ \\
\hline No data, $\mathrm{n}(\%)$ & $20(19.4)$ \\
\hline \multicolumn{2}{|l|}{ After pharmacogenetic testing } \\
\hline Median (range) HIV RNA (copies/mL) & $39(19-610,068)$ \\
\hline Undetectable ( $<40$ copies $/ \mathrm{mL}), \mathrm{n}(\%)$ & $76(73.8)$ \\
\hline Detectable, $\mathrm{n}(\%)$ & $17(16.5)$ \\
\hline No data, $\mathrm{n}(\%)$ & $10(9.7)$ \\
\hline \multicolumn{2}{|l|}{ At pharmacogenetic testing } \\
\hline Median (range) CD4 cell count (cells/mm³) & $329(11-1,121)$ \\
\hline$\leq 200$ & $25(24.3)$ \\
\hline $20 I-350$ & $31(30.1)$ \\
\hline $35 I-500$ & $23(22.3)$ \\
\hline$>500$ & $19(18.4)$ \\
\hline No data & $5(4.9)$ \\
\hline \multicolumn{2}{|l|}{ After pharmacogenetic testing } \\
\hline Median (range) CD4 cell count (cells/mm³) & $404(19-1,073)$ \\
\hline$\leq 200$ & $13(12.6)$ \\
\hline $201-350$ & $18(17.4)$ \\
\hline $351-500$ & $33(32.0)$ \\
\hline$>500$ & $32(31.1)$ \\
\hline No data & $7(6.80)$ \\
\hline \multicolumn{2}{|l|}{ Treatment status at the end of the study } \\
\hline Naive, n (\%) & $2(2.0)$ \\
\hline On antiretroviral therapy, $\mathrm{n}(\%)$ & $100(97.1)$ \\
\hline Tenofovir, lamivudine, efavirenz, n (\%) & $26(25.2)$ \\
\hline Tenofovir, emtricitabine, efavirenz, n (\%) & $22(21.4)$ \\
\hline Zidovudine, lamivudine, nevirapine, n (\%) & $7(6.8)$ \\
\hline No data, $\mathrm{n}(\%)$ & I (0.9) \\
\hline
\end{tabular}

Abbreviation: HIV, human immunodeficiency virus. 
Table 2 Number and prevalence of HLA-B genotypes in 79 HIV-infected patients

\begin{tabular}{|c|c|c|c|c|c|}
\hline & \multicolumn{5}{|l|}{ HLA-B* } \\
\hline & Normal & HLA-B*3505 & HLA-B*570I & HLA-B*400I & Other HLA \\
\hline Screening, $\mathrm{n}$ & 7 & 0 & 0 & 2 & 13 \\
\hline $\begin{array}{l}\text { Confirmation the } \\
\text { cause of skin rash, } n\end{array}$ & 0 & 1 & 2 & 1 & 2 \\
\hline ADRs besides rash, $\mathrm{n}$ & 16 & I & 0 & I & 12 \\
\hline Choice of next ARV, $n$ & 8 & 0 & 2 & I & 10 \\
\hline Total, n & 31 & 2 & 4 & 5 & 37 \\
\hline Prevalence (\%) & 39.2 & 2.5 & 5.1 & 6.3 & 46.8 \\
\hline
\end{tabular}

Abbreviations: ADRs, adverse drug reactions; ARV, antiretroviral drug; HIV, human immunodeficiency virus; HLA-B*, human leukocyte antigen-B*.

out of five patients who undergone $H L A-B * 4001$ genotyping developed lipodystrophy after receiving stavudine (four of them did not receive stavudine). One out of two patients who had positive $H L A-B * 3505$ developed skin rash after receiving NVP (the other one did not receive NVP).

Among 51 patients in whom CYP2B6 genotyping was performed for the management and/or prevention of EFV toxicity, $39.2 \%$ were extensive metabolizers. The most common $C Y P 2 B 6$ haplotypes were $C Y P 2 B 6^{*} 1 / * 1, C Y P 2 B 6^{*} 1 / * 4$, and $C Y P 2 B 6^{*} 1 / * 2$ with heterozygous mutant g. $21563 \mathrm{C}>\mathrm{T}$ (CT). Of these, $51.0 \%$ were intermediate metabolizers. The most common $C Y P 2 B 6$ haplotypes were $C Y P 2 B 6^{*} 1 / * 6$, $C Y P 2 B 6^{*} 1 / * 2$ with heterozygous mutant g. $18492 \mathrm{~T}>\mathrm{C}$ (TC), $C Y P 2 B 6^{*} 1 / * 5$ with homozygous mutant g. $18492 \mathrm{~T}>\mathrm{C}$ (CC), $C Y P 2 B 6^{*} 2 / * 4$ with mutations, and $C Y P 2 B 6 * 2 / * 6$ with mutations. The other $9.8 \%$ were slow metabolizers. Six out of 51 patients in whom CYP $2 B 6$ genotyping was performed had more than one mutation, five patients had two mutations, and one patient had three mutations.

Three out of five patients who were slow metabolizers had high EFV level $(4.246 \mu \mathrm{g} / \mathrm{mL}, 7.090 \mu \mathrm{g} / \mathrm{mL}$, and $4.013 \mu \mathrm{g} / \mathrm{mL})$. The CYP2B6 haplotypes of three patients were $C Y P 2 B 6^{*} 6 / * 6+$ homozygous mutant g.3003CC+g. $18492 C C+$ g. $21563 \mathrm{TT}, C Y P 2 B 6^{*} 6 /{ }^{*} 6$, and $C Y P 2 B 6^{*} 6 / * 6$. One patient did not undergo testing of EFV level. The last patient had $C Y P 2 B 6^{*} 6 / * 6+$ heterozygous mutant g.18492T $>$ C (TC), but the EFV level was normal $(2.093 \mu \mathrm{g} / \mathrm{mL})$. The CYP2B6 haplotypes and mutations of CYP2B6 are shown in Tables 3 and 4.

Regarding ADRs, 45 ADRs were skin rash. They could be categorized as 18 ADRs from tenofovir, 17 ADRs from EFV, four ADRs from zidovudine, two ADRs from abacavir, and one ADR each from NVP, raltegravir, ritonavir, and didanosine. Among other ADRs, the most common one of each drug was as follows: acute kidney injury from tenofovir, dizziness from EFV, anemia from zidovudine, hypersensitivity reaction from abacavir, and drug rash from NVP.
Out of a total of 103 patients, the treatment plan, including changing the drug regimens $(n=48)$, changing ARV dose for avoiding toxicity $(\mathrm{n}=2)$, and stopping $\operatorname{ARV}(\mathrm{n}=1)$, was adjusted after the physicians knew the results. ADRs, such as dizziness, insomnia, or depression from EFV or skin rash from abacavir, EFV, or NVP, were improved in $96.4 \%$ of patients with these complaints. Abnormal laboratory results, such as acute kidney injury or anemia, were improved which returned to normal or baseline in $59.3 \%$ of patients. HIV RNA was undetectable $(<40$ copies $/ \mathrm{mL}$ ) after adjusting the treatment in $94.9 \%$.

\section{Discussion}

This research is the study describing the use of pharmacogenetics in clinical practice for the treatment of individuals with HIV infection in Thailand, a resource-limited country. We found that the prevalence of $H L A-B * 5701, H L A-B * 3505$, and $H L A-B^{*} 4001$ was $5.1 \%, 2.5 \%$, and $6.3 \%$, respectively. Regarding the results of $C Y P 2 B 6,39.2 \%$ were extensive metabolizers, $51.0 \%$ were intermediate metabolizers, and $9.8 \%$ were slow metabolizers. Finally, we found that when the physicians modified treatment based on pharmacogenetic

Table 3 Prevalence of CYP2B6 predicted phenotypes in 5I HIVinfected patients

\begin{tabular}{|c|c|c|c|}
\hline & \multicolumn{3}{|l|}{ CYP2B6 } \\
\hline & $\begin{array}{l}\text { Extensive } \\
\text { metabolizer }\end{array}$ & $\begin{array}{l}\text { Intermediate } \\
\text { metabolizer }\end{array}$ & $\begin{array}{l}\text { Slow } \\
\text { metabolizer }\end{array}$ \\
\hline Screening, n & II & 17 & I \\
\hline $\begin{array}{l}\text { Confirmation of the } \\
\text { cause of skin rash, } n\end{array}$ & 1 & 2 & I \\
\hline $\begin{array}{l}\text { ADRs besides } \\
\text { rash, } \mathrm{n}\end{array}$ & 6 & 7 & 3 \\
\hline $\begin{array}{l}\text { Choice of next } \\
\text { ARV, } n\end{array}$ & 2 & 0 & 0 \\
\hline Total, $\mathrm{n}$ & 20 & 26 & 5 \\
\hline Prevalence (\%) & 39.2 & 51.0 & 9.8 \\
\hline
\end{tabular}

Abbreviations: ADRs, adverse drug reactions; $A R V$, antiretroviral drug; CYP2B6, cytochrome P 2B6; HIV, human immunodeficiency virus. 
Table 4 Prevalence of CYP2B6 genotypes and predicted phenotypes in 5 I HIV-infected patients stratified by the reasons of testing

\begin{tabular}{|c|c|c|c|c|}
\hline \multirow[t]{2}{*}{ Reasons and results } & \multicolumn{4}{|c|}{ CYP2B6 polymorphisms } \\
\hline & No mutation & $18492 \mathrm{~T}>\mathrm{C}$ & $21563 C>T$ & Other \\
\hline \multicolumn{5}{|l|}{ Screening $(\mathrm{n}=38)$} \\
\hline Extensive metabolizer, $\mathrm{n}$ & 2 & 8 & 1 & I \\
\hline Intermediate metabolizer, $\mathrm{n}$ & 3 & 12 & 3 & I \\
\hline Slow metabolizer, $\mathrm{n}$ & - & 1 & - & - \\
\hline No CYP2B6, n & - & - & - & - \\
\hline \multicolumn{5}{|c|}{ Confirmation of the cause of skin rash $(n=6)$} \\
\hline Extensive metabolizer, $\mathrm{n}$ & 1 & - & - & - \\
\hline Intermediate metabolizer, $\mathrm{n}$ & I & - & - & I \\
\hline Slow metabolizer, $\mathrm{n}$ & I & - & - & - \\
\hline No CYP2B6, n & - & - & - & - \\
\hline \multicolumn{5}{|l|}{ ADRs besides rash $(n=39)$} \\
\hline Extensive metabolizer, $\mathrm{n}$ & 1 & 5 & - & - \\
\hline Intermediate metabolizer, $\mathrm{n}$ & 1 & 5 & 2 & I \\
\hline Slow metabolizer, $\mathrm{n}$ & 2 & 1 & 1 & I \\
\hline No CYP2B6, n & - & - & - & - \\
\hline \multicolumn{5}{|l|}{ Choice of next ARV $(n=20)$} \\
\hline Extensive metabolizer, $\mathrm{n}$ & 1 & 1 & - & - \\
\hline Intermediate metabolizer, $\mathrm{n}$ & - & - & - & - \\
\hline Slow metabolizer, $\mathrm{n}$ & - & - & - & - \\
\hline No CYP2B6, n & - & - & - & - \\
\hline Total, $\mathrm{n}$ & 13 & 33 & 7 & 5 \\
\hline Prevalence (\%) & 22.4 & 56.9 & 12.1 & 8.6 \\
\hline
\end{tabular}

Note: Five patients had two mutations, and one patient had three mutations.

Abbreviations: ADRs, adverse drug reactions; ARV, antiretroviral drug; CYP2B6, cytochrome P 2B6; HIV, human immunodeficiency virus.

data, the treatment outcome was improved. In future, this data will be useful for the integration of pharmacogenetic testing into part of HIV clinical management of Thai National Health Care system.

The HLA markers $H L A-B * 5701, H L A-D R 7$, and HLA$D Q 3$ were reported to have positive predictive value for abacavir hypersensitivity of $100 \%{ }^{21} H L A-B * 5701$ prevalence in the present study was $5.1 \%$ which was comparable to that of the study in Thailand, $4 \%-10 \% .^{22}$ Low prevalence of $H L A-B * 5701$ of $2.5 \%$ (95\% confidence interval $3.0 \%-8.7 \%$ ) was determined among HIV-infected Thai children. ${ }^{23} H L A-B * 5701$ screening is recommended prior to initiating abacavir, especially in population with high prevalence or prevalence $>5 \%$ in some studies. ${ }^{23,24}$ However, it is not widely accessible in the resource-limited countries. ${ }^{25}$ According to our information obtained, routine screening for $H L A-B * 5701$ in Thailand prior to initiating abacavir should be performed because prevalence was $>5 \%$.

In comparison with previous study, $H L A-B * 3505$ prevalence in the present study was higher than in general Thai population $(2.5 \%$ vs $0.7 \%){ }^{26}$ The previous study in HIVinfected Thai patients determined that $H L A-B * 3505$ had a positive predictive value for NVP-induced skin rash of $17.5 \% .{ }^{17}$ In the present study, we identified that one out of two patients $(50 \%)$ with positive $H L A-B^{*} 3505$ developed
NVP-induced skin rash. HIV-infected patients in Asia who had late HIV diagnosis usually have polypharmacy. The common drugs that the patients often receive together at the point of $\mathrm{ARV}$ initiation are drug(s) for opportunistic infection (OI) prophylaxis (eg, co-trimoxazole and fluconazole) and $\operatorname{drug}(\mathrm{s})$ for treatment of OI(s) (eg, antituberculous drug). If $H L A-B * 3505$ can identify NVP-induced skin rash in Thai patients, the pharmacogenetic testing can help the physicians to confirm the diagnosis of skin rash from NVP. The modification of HIV management might be easier.

In this study, we determined a higher level of $C Y P 2 B \sigma^{*} 6 / * 6$ prevalence $(9.8 \%)$ than the previous larger study $(6.6 \%)$ in Thai patients coinfected with HIV and tuberculosis. ${ }^{9}$ The $* 6$ allele is associated with higher EFV plasma concentrations and an increased risk of CNS toxicity. ${ }^{8}$ Three out of five patients who were slow metabolizers had high level of EFV. One patient who had $C Y P 2 B 6^{*} 6 / * 6+$ heterozygous mutant g.18492T $>$ C (TC) had normal EFV level. This might be explained by the $18492 \mathrm{~T}>\mathrm{C}$ mutation associated with low EFV concentrations. In patients who had normal and low EFV level, confirmation of EFV level is recommended.

The strength of this study was that it was conducted in a resource-limited country, Thailand, which has the highest prevalence in Southeast Asia. There is only scanty information available regarding pharmacogenetics in clinical practice 
studies in resource-limited setting including Thailand; this study may lead to the implication of the test in real life.

However, there were several limitations. A major limitation was due to a small number of the study population. In addition, several biases in selection of patients were possible because of nature of retrospective analysis. Difference in economic status might be another bias because only in patients who were government officers or self-paid, pharmacogenetic testing could be performed. Lastly, the majority of HIV-infected patients in this study were male, and sex discrepancy may affect pharmacogenetic result. Due to all these limitations, the results from this study may not be applicable to general population until validation from prospective study with a larger sample size is obtained.

\section{Conclusion}

In conclusion, pharmacogenetic tests and therapeutic drug monitoring lead to improvement of medical treatment by creating individualized dosing regimen, maximizing drug efficacy, and minimizing drug toxicity. Benefits of pharmacogenetic screening in HIV patients help to not only reduce ADRs but also minimize HIV drug resistance. In future, the pharmacogenetic testing may be available in more hospitals and cheaper or free of charge for screening all HIV-infected Thai patients to improve quality of care.

\section{Disclosure}

The authors report no conflicts of interest in this work.

\section{References}

1. UNAIDS. UNAIDS report on the Global AIDS epidemic 2013; 2013 [Accessed March 4, 2015]. Available from: http://www.unaids.org/en/ resources/campaigns/20121120_globalreport2012/globalreport.

2. UNAIDS. Global report 2012: AIDS info 2012; 2012 [Accessed March 1, 2015]. Available from: http://www.unaids.org/en/dataanalysis/datatools/ aidsinfo.

3. UNAIDS. Global AIDS response progress reporting 2012; 2012. [Accessed March 1, 2015]. Available from http://www.unaids.org/sites/ default/files/en/media/unaids/contentassets/documents/document/2011/ JC2215_Global_AIDS_Response_Progress_Reporting_en.pdf.

4. Shet A, Antony J, Arumugam K, Kumar Dodderi S, Rodrigues R, DeCosta A. Influence of adverse drug reactions on treatment success: prospective cohort analysis of HIV-infected individuals initiating firstline antiretroviral therapy in India. PLoS One. 2014;9:e91028.

5. d'Arminio Monforte A, Lepri AC, Rezza G, et al. Insights into the reasons for discontinuation of the first highly active antiretroviral therapy (HAART) regimen in a cohort of antiretroviral naive patients. I.CO.N.A. Study Group. Italian Cohort of Antiretroviral-Naive Patients. AIDS. 2000;14:499-507.

6. Chantratita W, Kiertiburanakul S, Sungkanuparph S, CharoenyingwattanaA, Mahasirimongkol S. Integrating HIV-1 pharmacogenomics into the universal coverage health-care system in Thailand: from scientific evidence to policy. J Pharmacogenomics Pharmacoproteomics. 2011;S6:1-6.
7. Tozzi V. Pharmacogenetics of antiretrovirals. Antiviral Res. 2010;85: 190-200.

8. Sukasem C, Cressey TR, Prapaithong P, et al. Pharmacogenetic markers of CYP2B6 associated with efavirenz plasma concentrations in HIV-1 infected Thai adults. Br J Clin Pharmacol. 2012;74:1005-1012.

9. Manosuthi W, Sukasem C, Lueangniyomkul A, et al. Impact of pharmacogenetic markers of CYP2B6, clinical factors, and drug-drug interaction on efavirenz concentrations in HIV/tuberculosis-coinfected patients. Antimicrob Agents Chemother. 2013;57:1019-1024.

10. Sukasem C, Chamnanphon M, Koomdee N, et al. Pharmacogenetics and clinical biomarkers for subtherapeutic plasma efavirenz concentration in HIV-1 infected Thai adults. Drug Metab Pharmacokinet. 2014;29:289-295.

11. Cressey TR, Lallemant M. Pharmacogenetics of antiretroviral drugs for the treatment of HIV-infected patients: an update. Infect Genet Evol. 2007;7:333-342.

12. Clarke H, Mousa SA. The implications of pharmacogenomics in the treatment of HIV-1-infected patients of African descent. Pharmgenomics Pers Med. 2009;2:93-99.

13. Haas DW. Pharmacogenomics and HIV therapeutics. J Infect Dis. 2005;191:1397-1400.

14. Department of Disease Control MoPH. Thailand National Guidelines on HIV/AIDS Treatment and Prevention 2014. Thailand: 2014. Available from: http://www.thaiaidssociety.org/images/PDF/hiv_guideline_2557. pdf. Accessed March 1, 2015.

15. Wangsomboonsiri W, Mahasirimongkol S, Chantarangsu S, et al. Association between HLA-B*4001 and lipodystrophy among HIVinfected patients from Thailand who received a stavudine-containing antiretroviral regimen. Clin Infect Dis. 2010;50:597-604.

16. Ananworanich J, Moor Z, Siangphoe U, et al. Incidence and risk factors for rash in Thai patients randomized to regimens with nevirapine, efavirenz or both drugs. AIDS. 2005;19:185-192.

17. Chantarangsu S, Mushiroda T, Mahasirimongkol S, et al. HLA-B*3505 allele is a strong predictor for nevirapine-induced skin adverse drug reactions in HIV-infected Thai patients. Pharmacogenet Genomics. 2009;19:139-146.

18. Marzolini C, Telenti A, Decosterd LA, Greub G, Biollaz J, Buclin T. Efavirenz plasma levels can predict treatment failure and central nervous system side effects in HIV-1-infected patients. AIDS. 2001;15:71-75.

19. KDIGO. Clinical practice guideline for acute kidney injury 2012; 2012. [Accessed March 1, 2015]. Available from: http://www.kdigo.org/clinical_practice_guidelines/pdf/KDIGO\%20AKI\%20Guideline.pdf.

20. Longo DL, Fauci AS, Kasper DL, Hauser SL, Jameson JL, Loscalzo J. Harrison's Principles of Internal Medicine. 18 ed. New York: McGrawHill; 2012.

21. Mallal S, Nolan D, Witt C, et al. Association between presence of HLA-B*5701, HLA-DR7, and HLA-DQ3 and hypersensitivity to HIV-1 reverse-transcriptase inhibitor abacavir. Lancet. 2002;359:727-732.

22. Nolan D, Gaudieri S, Mallal S. Pharmacogenetics: a practical role in predicting antiretroviral drug toxicity? J HIV Ther. 2003;8:36-41.

23. Puthanakit T, Bunupuradah T, Kosalaraksa P, et al. Prevalence of human leukocyte antigen-B*5701 among HIV-infected children in Thailand and Cambodia: implications for abacavir use. Pediatr Infect Dis J. 2013;32:252-253.

24. Phillips EJ. Genetic screening to prevent abacavir hypersensitivity reaction: are we there yet? Clin Infect Dis. 2006;43:103-105.

25. Park WB, Choe PG, Song KH, et al. Should HLA-B*5701 screening be performed in every ethnic group before starting abacavir? Clin Infect Dis. 2009;48:365-367.

26. Middleton D, Menchaca L, Rood H, Komerofsky R. New allele frequency database: http://www.allelefrequencies.net. Tissue Antigens. 2003;61:403-407. 


\section{Publish your work in this journal}

Pharmacogenomics and Personalized Medicine is an international, peerreviewed, open access journal characterizing the influence of genotype on pharmacology leading to the development of personalized treatment programs and individualized drug selection for improved safety, efficacy and sustainability. This journal is indexed on the American Chemical
Society's Chemical Abstracts Service (CAS). The manuscript management system is completely online and includes a very quick and fair peer-review system, which is all easy to use. Visit http://www.dovepress. com/testimonials.php to read real quotes from published authors.

Submit your manuscript here: http://www.dovepress.com/pharmacogenomics-and-personalized-medicine-journal 